\title{
NOTAS
}

\section{NEUTRO, COLEGTIVO E IDENTIFICACIÓN DE MASA}

Las formas castellanas éste, ésta y esto se han clasificado generalmente según el género gramatical (masculino, femenino, neutro). Este esquema, que proviene de la gramática latina, depende de la interpretación del neutro como término negativo: Bello, por ejemplo, nota que "neutro quiere decir ni uno ni otro, esto es, ni masculino ni femenino" 1 . Rodolfo Lenz distingue entre el "neutro pronominal" (ello, esto, algo, qué) y el género gramatical de los sustantivos: "entiéndase neutro en su sentido primitivo 'ni uno ni otro', es decir, ningún género". Lenz prefiere el término "colectivo" porque estas formas "siempre expresan un conjunto, no un concepto aislado" 2 . La diferencia entre la interpretación de Bello y la de Lenz radica en las orientaciones del criterio empleado: substitución por lo, ello (Bello) y colectividad semántica (Lenz). Es difícil reconciliar estos puntos de vista. Como nota Bello, los géneros del castellano no tienen relación específica con la categoría semántica de las formas asi distinguidas (p. 373, nota 8), salvo entre formas personales o animadas, las cuales nunca permiten substituciones neutras $(\S 295)$.

Mientras que Lenz propone la interpretación colectiva del neutro, Bello afirma que el neutro significa "ya unidad, ya pluralidad colectiva" (ibid.). Gili Gaya también acepta esta función doble del neutro: "la substantivación con lo da al adjetivo carácter abstracto y colectivo, mientras que con el artículo masculino (definido o indefinido) tiene significación concreta e individual" "3. Sin embargo, este análisis está en contradicción con unos usos comunes del neutro castellano. En la oración "El tráfico es lo peor de la ciudad", lo peor no representa colectividad ni abstracción, ya que equivale a la cosa peor. En cambio, la idea de que las formas masculinas (o femeninas) representen entidades de un modo "concreto e individual" no explica los nombres masa como la pobreza, la su. tileza, el valor, la arena. Si lo que representa algo abstracto y no-específico y el que representa algo concreto y específico, es imposible explicar frases como Hago lo que dices, Haré lo que digas; El que gana el premio va a Francia, El que gane el premio irá a Francia. El grado de especifici-

1 Gramática de la lengua castellana, Caracas, 1972, $\S 293$. Esta edición es reimpresión del t. 4 de las Obras completas de Bello, Caracas, 1951.

2 La oración y sus partes, 2a ed., Madrid, 1925, § 194.

3 Curso superior de sintaxis española, 9a ed., Barcelona, 1964, p. 224. 
dad no reside en la distinción lo que: el que, sino que está marcado por el modo del verbo. Por eso, lo que puede ser específico y $e l$ que puede ser no-específico.

Otro problema de análisis tradicionales del neutro lo es el concepto de antecedente. William Bull dice que "todos los números privados, y todas las unidades privadas de medida, pueden usarse a la iniciación del enfoque común para referirse a entidades que previamente no se han mencionado ni identificado. Claro está que las formas no tienen nada con qué concordar en género y por lo tanto pueden considerarse como neutras" " ${ }^{4}$. Esta definición del género neutro, además de ser negativa, es difícil de aplicar a casos en que formas como esto reproducen a varios sustantivos que las preceden; es decir, en su empleo colectivo.

Uno de los puntos implícitos en los conceptos de los escritores citados es que el neutro carece de la posibilidad de pluralización. En general, los gramáticos han considerado el neutro eso, lo que como singulares y gramaticalmente lo son (eso es bueno; lo que me gusta). Sin embargo, semánticamente vale más considerar el "neutro" como "neutro", no en género, sino en número. La tesis que intentaremos demostrar en la discusión que sigue es ésta: los neutros lo que y eso corresponden semánticamente a una noción de masa, mientras que el (la) que y ése (ésa) seleccionan de entre entidades contables previamente identificadas en cuanto a sus características masa. La idea de la identificación de masa del neutro ayuda a explicar 1) la falta de formas neutras en el plural, y 2) la imposibilidad de referencia personal de los neutros ${ }^{5}$. No tiene sentido esforzarse por encontrar sustantivos a los que se refieran los neutros: los antecedentes pueden ser nombres, adjetivos, infinitivos, verbos, $\mathrm{u}$ oraciones completas; y no es necesario que haya antecedente (iQué es eso?). Pero este hecho no implica que el neutro sea menos específico que las formas masculinas o femeninas.

Los paralelos entre el que y lo que incluyen su construcción con los interrogativos ${ }_{i} q u e ́$ ? y ${ }_{G} c u a ́ l$ ? Son gramaticales estas oraciones:

1. ¿Cuál es el que busca?

2. ¿Qué es lo que busca?

Pero no éstas:

3. ¿Cuál es lo que busca?

4. ¿QQué es el que busca? 6

4 Spanish for teachers: Applied linguistics, New York, 1965, pp. 250-251.

5 "Un conjunto de seres personales - dice Bello $\$ 295-$ no podría ser reproducido por un sustantivo neutro".

6 Es posible la oración ¿Qué es el que busca? sólo en un contexto muy restringido. El que debe referirse a una persona, por la convención sociolingüística que así identifica a varios plurales sin antecedente, como unos, todos, los que, etc. Pero, de acuerdo con otros casos que veremos más adelante, ¿qué? pide una identificación general (es católico, es médico). La falta de artículo en estas respuestas nos ayuda a comprender la naturaleza no contable de dicha identificación. Por otra parte, al decir es un médico mediocre, con artículo, usamos un nombre contable que implica distincio- 
Nótense también:

5. ¿Qué compró? Lo que vimos ayer.

6. ¿Qué compró? *El que vimos ayer.

La oración 3 no es aceptable porque pide una selección (Gcuál? ) de una masa no identificada (lo que). En la 4 el que identifica una categoría de entidades y $6 q u e ́$ ? pide esta categoría, por lo cual la oración resulta de fectuosa. En la 6, la pregunta pide la identificación de masa y la respuesta selecciona de entre elementos contables cuya identificación de masa es requisito de esta misma selección.

En su construcción con $6 q u e ́$ ? y ícuál? el neutro presenta semejanzas con los sustantivos abstractos como la valentia, la sabiduria. Por eso, notan algunos gramáticos que lo sórdido puede corresponder a la sordidez, y lo útil a la utilidad. Pero los abstractos constituyen sólo una porción de los nombres masa, como el arroz, la arena y la hierba, que identifican masas en el singular y variedades (o realizaciones) en el plural (las hierbas de la Florida, los cafés mexicanos). La referencia a variedades o realizaciones es posible también cuando se usan nombres masa con números, hasta con el artículo indefinido (un café bueno: una variedad buena de café; una locura: un ejemplo de la locura en abstracto, etc.). Es notable que estos nombres masa combinan con elementos interrogativos precisamente como las formas llamadas "neutras":

\section{7. ¿Cuál es la valentia?}

A menos que se refiera a una selección de definiciones previamente dadas, la oración 7 pide una selección de entre realizaciones de una masa no identificada (la valentía en abstracto): el defecto de la 7 es idéntico al de la 3. Sin embargo, la 7 puede referirse a variedades (contables) de valentía si añadimos modificación por adjetivo, y en este caso įcuál? se emplea correctamente:

\section{8. ¿Cuál es la valentía que más hace falta?}

Es decir, ¿Cuál es la variedad (contable) de valentia? Nótese también la diferencia entre estas oraciones:

9. ¿Qué prefiere estudiar, la biología o la química? ${ }^{\top}$

10. Lo que prefiero estudiar es la biología.

nes dentro de la clase-masa médico. Nótese que es un médico mediocre no parece ser una contestación natural a la pregunta iQué es el que busca? Esta pregunta no establece (es "neutra" a) distinciones de clase dentro de la masa de que se trata (médica).-En un estudio reciente, "On the use of the indefinite artiele", $H, 61$ (1978), 105-109, John M. Lipski observa que "el articulo indefinido se ve engendrando una configuración marcada, que envuelve una especificación semántica adicional, la de una característica limitadora que no se encuentra en frases en que se ha omitido el artículo" (p. 108). Aunque Lipski entra luego en distinciones semánticas discutibles (conducta externa: característica interna, rasgos inherentes: rasgos voluntarios), lo que aqui importa es el contraste masa: individuo entre uno y otro caso.

7 Estos ejemplos provienen de Aurelio M. Espinosa Jr., y John P. Wonder, Gra- 
11. ¿Cuál estudia Ud., esta lección o ésa?

12. La que estudio es ésta.

La oración 9 pide una identificación de una masa, aunque es una selección de entre dos nombres masa ,y lo que se refiere a la masa de la contestación en la 10). La oración 11 escoge de entre dos entidades contables, y la que de la 12 contesta con la selección deseada.

Esta relación entre ¿qqué?, lo que, y los nombres masa se encuentra en la identificación de masas no contables, identificación que por definición no puede referirse ni a seres personales ni al número plural. Notamos la misma relación con los sustantivos masa de medida como el arroz:

13. Este arroz es el que buscaba.

14. Este arroz es lo que buscaba.

En la 13, interpretamos arroz como contable (este arroz es la variedad de arroz que buscaba). En la 14, lo que requiere que se interprete arroz como masa no contable. Las dos frases no difieren una de otra por su especificidad, sino por su relación con masa o con selección de entidades contables, según el caso.

Vemos otra vez esta distinción con unos verbos. En general, conocer ocurre solamente con entidades contables (icuál?, el que, plural) y saber ocurre con la identificación de masas (iqué?, lo que, "neutro" numérico) :

15. ¿Qué sabías? Eso es lo que sabía.

16. ¿Cuál conocías? Ése es el que conocía.

Aunque saber puede usarse con nombres contables (el poema que sabia, el que sabia), es muy raro conocer con la identificación de masa (*lo que conocia, *conocía eso). Saber se emplea muchas veces con objetos directos sentencíales, los cuales han de interpretarse como masa (sabia que Jaime venia, lo sabia, sabia eso, ¿qué sabias?). Mientras que saber se refiere a masas y rara vez a entidades contables, conocer se relaciona sólo con éstas. Ya que ni nombres masa ni formas "neutras" pueden referirse a seres personales, se sigue que saber no admite objetos directos que nombran a personas:

17. Conozco a Pedro.

18. *Sé a Pedro.

Al parecer, saber, cuando se usa con entidades contables, significa casi siempre saber recitar: saber el poema, la canción, el número. La recitación misma corresponde a la realización de la categoría de lo recitado.

mática analitica, Lexington, Mass., 1976, p. 248. Espinosa y Wonder dicen que "estas formas suelen denominarse "neutros'. Sin embargo, el neutro del latín puede referirse a cosas concretas". Los escritores prefieren el término "abstracto" (p. 179) . Hay que añadir que también existen abstractos masculinos y femeninos, en lo que toca al significado léxico. 
Saber pertenece a una clase de verbos que admiten objetos sentencíales, siempre "neutros" en lo tocante al número:

19. Lo que dijo me enfada. ¿Qué dijo? Dijo eso.

20. Lo que creía me enfada. ¿Qué creía? Creía eso.

Muchos otros verbos transitivos se usan con masa o con entidades contables:

21. Lo que señaló (hizo, pidió) me enfada. ¿Qué señaló (hizo, pidió) ? Señaló (hizo, pidió) eso.

22. El que señaló (hizo, pidió) me enfada. ¿Cuál señaló (hizo, pidió) ? Señaló (hizo, pidió) ése.

En lo que hizo me enfada, hacer significa 'ejecutar' y lo ejecutado se interpreta como masa. En el que hizo me enfada, hacer significa 'construir' o 'crear' y el objeto se interpreta como nombre contable.

El neutro también figura en unas construcciones con lo más sustantivo. La teoría transformacional trata a lo bueno como síncope de lo que es bueno, paralelo a el (que es) bueno s. El español, que en muchos casos permite variación entre adjetivos y nombres (muy señor mio; son católicos), también permite la transformación lo que es poeta $\longrightarrow$ lo poeta. Este uso representa la única forma masa que puede referirse a personas. En casi todos los ejemplos de lo más nombre, el nombre es de persona (lo rey, lo capitán, lo santo, lo mujer, lo andaluza) ${ }^{9}$. La rareza de esta construcción se explica si vemos que los nombres de persona casi nunca están identificados con masas indivisibles. El nombre masa lo poeta significa lo que es un poeta, no como individuo contable, sino como masa indivisible aunque posiblemente múltiple ${ }^{10}$.

Una de las críticas que hizo Rufino José Cuervo a Bello versó sobre su

8 Véase Espinosa y Wonder, op. cit., p. 180.

9 Véanse los ejemplos en la Gramática de Bello, § 974. Parece ser el otro patrón posible a lo más nombre o adjetivo: a lo antiguo, vive a lo millonario, se comporta a lo gran dama, se disfrazó a lo fin de siglo. Véase Yolanda R. SolÉ y Carlos A. Solé, Modern Spanish syntax: A study in contrast. Lexington, Mass., 1977, p. 297. Esta construcción $a$ lo + sustantivo se refiere a estilos o maneras de actuar en forma adverbial, y está en competencia con la construcción a la + adj. femenino (a la francesa, a la antigua, a la moderna). Parece que a la francesa, etc., provienen de nominalizaciones de adjetivos (a la [usanza] francesa), mientras que se emplea exclusivamente lo con nombres: $a$ lo señor (véase MARATHON MoNTrose RAMsey, $A$ textbook of modern Spanish, New York, 1967, pp. 570-571, y nota, p. 571). La función de $a$ en estas adverbializaciones de manera se da en general en frases hechas: andar a gatas, matarlo a sangre frí, lo hago a mi manera, etc. (Véase Ramsey, p. 541).

10 Bello lice: "No... condenaríamos como ajeno del castellano: «En Isabel la Católica no era menos grande la mujer que la reina». Lo sería sin duda la expresión propia, porque nos haría ver en mujer y reina dos cualidades, como lo son realmente. Pero la, figurando las cualidades como personas distintas, es una metáfora que hermosea y engrandece el concepto" ( $\$ 975$, p. 279) . Es típica del español esta caracterización masa de seres humanos, aunque es extremadamente rara con otros nombres contables. Falta por esto un miembro en la analogía lo mujer : lo mujeril : *lo libro : lo libreril. 
interpretación del infinitivo como sustantivo neutro. En su nota (Bello, nota 70, pp. 443-445) Cuervo parece preferir la interpretación verbal. Bello observa que el infinitivo no tiene relación sistemática con la categoría temporal del verbo: no indica la persona, el número ni el tiempo (nota 9, p. 375). Cuervo sugiere que el condicional tampoco tiene referencia al tiempo (dijo que vendria ayer; dijo que vendria ahora; dijo que vendria mañana: p. 445), a pesar de lo cual todos aceptan la forma condicional como verbo. Está claro que la crítica de Guervo es defectuosa. El condicional tiene relación con el tiempo en que denota la posteridad relativa a una anterioridad (Bello, $\$ 634$, p. 181). En efecto, el condicional significa sólo que una acción ocurrirá después de otra ya terminada, por lo que puede usarse -como en los ejemplos de Cuervo- con los distintos adverbios temporales.

Cuando Bello acepta el infinitivo como nombre, arguye que es neutro, usando su criterio de substitución por ello, lo: "Estábamos determinados a partir, pero hubo dificultades en ello, y tuvimos que diferirlo" ( $\$ 294$, p. 95). No importa que formas masculinas como el acompañen al infinitivo (el vivir mio): lo mismo ocurre en cuanto a bueno en lo otro bueno. Si el "neutro" identifica el significado de masas, podremos comprobar el análisis de Bello. Es notable, en primer lugar, que los infinitivos que se han añadido a la lengua como sustantivos léxicos representan, por lo general, nociones no contables en el singular (el placer, el deber, el poder, el ser). Unos han pasado a un estado de contabilidad (los [dos] decires, los seres humanos, un quehacer, sus haberes). Pero esto ocurre exclusivamente con los verdaderos nombres (que serian substituidos por él: ellos). En estos casos, la relación semántica entre el singular y el plural es idéntica a la de locura : locuras.

a) la locura : el ser : el cantar (en abstracto)

b) una (esa) locura : un (ese) ser : un (ese) cantar (contable)

c) las locuras : los seres : los cantares (contable) ${ }^{11}$

Sólo con gran dificultad es posible pluralizar los infinitivos que no se interpretan como nombres léxicos (masculinos): *los hablares, *los leeres, *los comeres, *los dormires.

El infinitivo, tanto como el "neutro" tradicional, se refiere a una masa numéricamente "neutra" y se comporta gramaticalmente como las otras formas "neutras" ya indicadas:

23. ¿Qué es (el) dormir?

24. *¿Cuál es (el) dormir?

25. Lo que quiere es dormir.

26. *El que quiere es dormir.

Ya que conocer no suele permitir objetos directos neutros, también se puede explicar el error de la 28 :

11 Otra vez las formas plurales indican realizaciones o ejemplos de la masa sin. gular no contable: un ejemplo de locura, una realización de ser. 
27. Sé leer hebreo.

28. * Conozco leer hebreo.

Bello dice que "aseméjase [el infinitivo] en su significación a los sustantivos abstractos. Teme $[r]$ y temor, por ejemplo, expresan una misma idea" ( $\$ 420$, p. 129 ). Sugiero que esta semejanza se debe a que tanto los abstractos como los infinitivos identifican conceptos no contables.

La interpretación del "neutro" en el sentido numérico (no genérico) muestra que no es necesario postular diferencias de especificidad o abstracción entre esto y éste. Esto es tan específico como éste, pero se refiere a una masa indivisible. Lo que estoy leyendo es más específico y definido que las que lea mañana. El "neutro" numérico presenta paralelos a los nombres masa, no solamente los abstractos (la castidad) sino también los de medida (el arroz). Stockwell, Bowen y Martin hacen caso omiso del "neutro" al decir que todos los artículos son déicticos "que se refieren a alguien o a algo ya en el enfoque (contexto) proveído por la comunicación; esto puede ser una entidad o persona ya mencionada o puede ser una entidad o persona única en la cultura" ${ }^{12}$. Nos parece que lo se omite de esta observación por un énfasis excesivo en la contabilidad. Vemos más claramente el sistema de los pronombres castellanos si aceptamos que éstos pueden hacer referencia tanto a masas indivisibles como a entidades contables.

Marquette University.

BARRY L. VelLEMAN

\section{ORDEN DE LOS PRONOMBRES ATONOS DURANTE EL PRIMER GUARTO DEL SIGLO XVI EN EL ESPAÑOL NOVOHISPANO}

Sin lugar a dudas, la colocación de los pronombres con respecto al verbo es uno de los puntos más interesantes de sintaxis histórica. En el castellano medieval, el pronombre normalmente se anteponía o se posponía al verbo de acuerdo con el lugar que ocupara el verbo dentro del sintagma oracional ${ }^{1}$, mientras que, en el español moderno, la enclisis

12 Robert P. Stock weld, J. Donald Bowen y John W. Martin, The grammalical structures of English and Spanish, Chicago, 1965, p. 65.

1 Es decir, la posición del pronombre dependía del contexto. Se posponía cuando el verbo se hallaba en posición inicial absoluta (dexóla), tras pausa anterior (de mea mater; tornese a meos germanos), después de las conjunciones mas y $e$ (e tornóse) y cuando un infinitivo absoluto aparecía después de una preposición (por sacar. los). En los demás casos, el pronombre solía anteponerse al verbo, sobre todo si el verbo se encontraba tras $s i, y a$, que (ke $l i$ fican) y no (non $s e$ burgundian). Con el infinitivo y el gerundio subordinados, si el sujeto de los dos verbos era el mismo, el pronombre pasaba al verbo regente (estaualos catando), pero si el sujeto era diferente, el verboide conservaba su pronombre (veriedes armarse moros). Cuando dos infinitivos o dos gerundios estaban regidos por el mismo verbo, el segundo verboide mantenía su pronombre (mando vos ... vestir e guarnirvos). Si el gerundio, el infinitivo 